\title{
EDUCAÇÃO ESPECIAL/INCLUSIVA NO BRASIL: demandas contemporâneas
}

\author{
SPECIAL EDUCATION / INCLUSIVE IN BRAZIL: conteporary demands \\ EDUCACIÓN ESPECIAL/INCLUSIVA EN BRASIL: demandas contemporáneas
}

\author{
Ivanilde Apoluceno de Oliveira \\ Professora Doutora do Programa de Pós-Graduação em Educação da Universidade do Estado do Pará. \\ Pós-Doutora em Educação pela PUC-Rio. \\ nildeapoluceno@uol.com.br
}

\begin{abstract}
RESUMO: Neste artigo analisamos as demandas que emergem do processo de implantação da política de inclusão na Educação Especial no Brasil.Demandas referentes a novos sujeitos; a formação e prática, que envolve o debate sobre o currículo, e o atendimento educacional na educação inclusiva. Este estudo tem por base pesquisas realizadas em municípios do Estado do Pará e,também, o levantamento bibliográfico sobre a educação inclusiva no Brasil, incluindo análise de documentos sobre a legislação referente à política da Educação Especial.O estudo aponta que há necessidade de se evidenciar as demandas, problematizar a política, que não atende as especificidades regionais, mas sobretudo, apontar pistas, caminhos teóricos e metodológicos para a inclusão escola e social do aluno público-alvo da Educação Especial.
\end{abstract}

PALAVRAS-CHAVE: Educação Especial. Política de Inclusão. Demandas contemporâneas.

ABSTRACT: In this article we analyze the emerging demands from the implementation process of inclusion policy on Special Education in Brazil. Demands related to new subjects; training and practice, evolving the debate on curriculum, and educational services in inclusive education. This study is based on surveys conducted in municipalities in the State of Pará and, Also the literature on inclusive education in Brazil, including document analysis on legislation referring to the Special Education policy. The study points out that there is need to highlight the demands, problematize politics, that does not meet specific regional characteristics, but above all, point out hints, theoretical and methodological approaches to include school and social of the Special Education student audience.

KEYWORDS: Special education. Inclusion Policy. Contemporary demands.

RESUMEN: En este artículo analizamos las demandas que surgen del proceso de implementación de la política de inclusión en la Educación Especial en Brasil. Demandas relacionadas con nuevos sujetos, la formación y práctica, que implican el debate sobre el currículo y el atendimiento educativo en la educación inclusiva. Este estudio se basa en investigaciones realizadas en municipios del Estado de Pará y también la literatura sobre la educación inclusiva en Brasil, incluyendo el análisis de documentos de la legislación sobre la política de Educación Especial. El estudio señala que existe la necesidad de poner de relieve las demandas, cuestionar la política, que no cumple con las especificidades regionales, pero, sobre todo, señalar caminos, enfoques teóricos y metodológicos para la inclusión escolar y social del alumno público clave de la Educación Especial.

PALABRAS CLAVE: Educación Especial. Política de Inclusión. Demandas contemporáneas. 
EDUCAÇÃO ESPECIAL/INCLUSIVA NO BRASIL | Ivanilde Apoluceno de Oliveira

\section{1| INTRODUÇÃO}

A Política de Inclusão na Educação Especial, no Brasil, substitui, nos anos 90, a política de Integração. Entretanto, a educação inclusiva é, também, anseio de educadores e movimentos sociais que lutam pelo direito de todos a uma educação de qualidade, que respeite as diferenças individuais e culturais e supere a exclusão social e educacional de segmentos sociais, entre os quais, o público alvo da Educação Especial.

A política de Integração pauta-se em uma concepção de abordagem individualista ao centrarse nas condições pessoais do aluno, nas suas possibilidades de adaptação ao processo escolar. Neste sentido, não problematiza as estruturas das instituições educacionais, pois é o aluno que, dependendo de suas condições físicas e psicológicas, integra-se ao sistema educacional. Nesta política, a escola não considera as diferenças individuais e culturais das crianças em sua organização social, transferindo para os educandos a adaptação ao modelo escolar existente.

A política de inclusão apresenta novos paradigmas teóricos ao deslocar o enfoque individual, centrado no aluno, para a escola, reconhecendo no seu interior a diversidade de diferenças: individuais, físicas, culturais e sociais.

A Resolução CNE/CEB N² 2/ 2001 destaca que existem princípios pedagógicos a serem seguidos, no processo de inclusão escolar, entre os quais, o de educar para a diversidade, que consiste no respeito às diferenças individuais e culturais dos indivíduos

A educação especial passa a ser compreendida inserida na educação geral, compreendendo-se que todos aprendem juntos, convivendo com as diferenças individuais e socioculturais. A educação inclusiva pressupõe que os educandos se desenvolvem melhor em um ambiente escolar diverso, compartilhando múltiplas experiências de vida, do que segregados em classes ou escolas especiais (OLIVEIRA, 2005).

Desta forma, a política de inclusão busca romper com a situação de exclusão que o público alvo da Educação Especial vem experienciando historicamente no contexto social, assumindo a escola a responsabilidade de promover a inclusão educacional, superando a desvinculação entre educação regular e a educação especial, bem como democratizando o espaço escolar. A inserção do aluno nas classes regulares democratiza a escola, já que as classes especiais colaboram para a segregação, a discriminação e a não participação do aluno público alvo da educação especial no contexto escolar global.

Para realizar a política de inclusão as escolas precisam realizar mudanças estruturais, nas ações pedagógicas e na formação de professores. Mudanças que perpassam por uma estrutura física adequada e adaptada às necessidades específicas dos educandos, um currículo flexível, práticas com novas propostas pedagógicas e formação continuada de professores para a inclusão escolar. Além disso, o fato da política de inclusão, por meios legais, garantir a matrícula do público alvo da Educação Especial nas escolas; viabilizar o debate sobre a inclusão tanto nas escolas quanto na sociedade e implantar nas redes públicas e privadas de ensino a política, por meio de salas de recursos multifuncionais, de forma hegemônica, para todo o Brasil, apresenta algumas demandas, que serão objetos de nossas reflexões neste estudo.

Organizamos o estudo sobre as demandas emergentes na política de educação inclusiva no Brasil em quatroseções: (1) caminhos metodológicos; (2) novos sujeitos da educação inclusiva; (3)formação e prática para inclusão escolar; (4) o atendimento educacional na educação inclusiva. 
EDUCAÇÃO ESPECIAL/INCLUSIVA NO BRASIL | Ivanilde Apoluceno de Oliveira

\section{2 | CAMINHOS METODOLÓGICOS}

As demandas apresentadas neste texto têm por base dados pesquisas que realizamos sobre a educação inclusiva.

A primeira " A prática de escolarização inclusiva e o atendimento especializado na Amazônia Paraense, concluída em 2013, financiada pelo PROESP-CAPES, e vinculada à Rede de Educação Inclusiva na Amazônia Paraense, sob a coordenação da Universidade do Estado Pará. Envolveu pesquisadores da UEPA, UFPA e UFOPA e foi realizada em 08 municípios do Pará: Belém, Ananindeua, Marituba, Marabá, Santarém, Barcarena, Tucuruí e Altamira (OLIVEIRA, 2013). A segunda, "Atendimento educacional em Salas de Recursos Multifuncionais de Escolas da Rede Municipal de Belém, concluída em 2014, financiada pelo CNPq e vinculada ao Observatório Nacional de Educação Especial, sob a coordenação nacional da UFSCAR. Envolveu pesquisadores da UEPA e UNIFESSPA e foi realizada nos municípios de Belém e Marabá (OLIVEIRA, 2014). A terceira, "Educação em classes multisseriadas na Amazônia: singularidade, diversidade e heterogeneidade", concluída em 2011e financiada pela CAPES. Possui vínculo com o Programa de Pós-Graduação em Educação da Universidade do Estado do Pará e foi realizada em dois municípios de Moju e Santarém (OLIVEIRA; FRANÇA; SANTOS, 2011).

Todas as pesquisas realizadas foram de campo, de abordagem qualitativa, realizadas em escolas públicas de municípios de Belém, cujas estratégias metodológicas foram levantamento bibliográfico e documental, realização de entrevistas semiestruturadas individuais e coletivas, por meio de grupos focais. A pesquisa realizada em parceria com a UFSCAR se configura, também, como colaborativa.

Os sujeitos foram professores e técnicos das escolas públicas pesquisadas. Contou-se, ainda, em uma das pesquisas, com coordenadores da Educação Especial de redes municipais de Ensino do Estado do Pará.

Neste estudo sobre as demandas da Educação Especial com a implantação da política de inclusão efetivamos, ainda, levantamento bibliográfico sobre a educação inclusiva no Brasil, incluindo análise de documentos sobre a legislação referente à política da Educação Especial.

\section{3 | NOVOS SUJEITOSDA EDUCAÇÃO INCLUSIVA}

Apesar de oficialmente a política de educação inclusiva na Educação Especial direcionar o atendimento educacional especializado para pessoas com deficiência, transtornos de desenvolvimento global e altas habilidades, a inclusão escolar no cotidiano da escola atende à demanda de novos sujeitos, isto é, alunos com diferentes síndromes, transtornos mentais, dificuldades de aprendizagem, entre outras. Inclusive, o atendimento de crianças autistas foi mencionado pelos professores como nova demanda (OLIVEIRA, 2014)

O público-alvo da Educação Especial e esses novos sujeitos apontam a demanda de nova formação e prática pedagógica para a inclusão escolar.

\subsection{Formação e prática pedagógica para a educação inclusiva}

A formação de professores para uma educação inclusiva nos cursos superiores é uma das principais demandas apontadas pelos docentes entrevistados.O que caracteriza essa formação?

Compreendemos que a formação e a prática pedagógica para a educação inclusiva envolvem estudos sobre novos paradigmas educacionais, o deslocamento do olhar de ações individuais e competitivas para coletivas e solidárias e o debate sobre novos saberes e práticas. 
a) Formação com novo paradigma: a educação inclusiva.

Nos Cursos de formação de docentes do ensino comum, o que significa implementar conteúdos de educação especial nos currículos dos Cursos? É incluir disciplinas de educação especial? Quais disciplinas? De fundamentos? Metodologias? Quantas disciplinas são necessárias? Essas disciplinas englobam as diversas especificidades da educação especial? Como trabalhar essa formação sem a fragmentação disciplinar?

É importante que a educação especial não se apresente nos Cursos de formação como mais uma "disciplina curricular" imposta por uma exigência legal, mas que de fato o objetivo de uma educação inclusiva, seja "diretriz" dos cursos de formação de professores (OLIVEIRA, 2002), o que pressupõe nos projetos pedagógicos a ruptura com o modelo tradicional presente ainda na estrutura curricular de alguns Cursos de Ensino Superior.

As demandas nos cursos de formação docente também estão presentes na formação continuada dos professores nas escolas. Essa formação é criticada pelos professores porque nem todos tem acesso e quando é ofertada nem sempre é de ensino de qualidade, interferindo muito pouco na prática cotidiana escolar (OLIVEIRA, 2014).

A educação inclusiva requer como demanda uma formação do educador numa perspectiva pedagógica humana, ética, social e política. Educação crítica e compromissada com a inclusão social, que articule teoria e prática.

b) Formaçãoe prática coletiva e solidária

A educação inclusiva nas escolas aponta para a necessidade de superação de práticas individualistas e competitivas para um trabalho coletivo, interdisciplinar e multiprofissional.

A inclusão escolar "requer trabalho coletivo, responsabilidades compartilhadas, envolvendo equipe técnica e professores, e também exercício de ações cooperativas" (CAVALCANTI, 2008, p. 243).Isto significa que na formação para a educação inclusiva esta prática precisa ser trabalhada teórica e metodologicamente.

Que fundamentos teóricos são necessários para o desenvolvimento de ações pedagógicas coletivas e interdisciplinares?

O trabalho coletivo na educação inclusiva segundo Machado (2008, p. 74) demanda o paradigma da complexidade porque "leva em conta a multiplicidade humana, a religação dos saberes e as relações cotidianas".

Oliveira (2015) explica que Edgar Morin, por meio da razão aberta estabelece, no campo da ciência, a religação dos saberes. Essa razão incorporasaberes do cotidiano de diferentes sujeitos e culturas e possibilita reconhecer a razão na alteridade, ou seja, o reconhecimento da "razão do outro". Destaca, ainda, a autora, que para Dussel reconhecer a razão do outro significa:

compreender que os saberes construídos pelos grupos sociais historicamente excluídos não são desprovidos de uma estrutura lógica e racional, nem simples reflexo da realidade, mas o próprio complexo simbólico que possibilita aos grupos relacionarem-se com a realidade e instituírem a vida cotidiana (OLIVEIRA, 2015, p.66).

Além do paradigma da complexidade, debater a diferença no âmbito educacional requer estudos sobre a interculturalidade, porque a prática vigente nas escolas é a tradicional voltada ao "aluno padrão", centrada no conteúdo escolar universalista e monocultural, que não dá conta para trabalhar com as diferenças. 
A educação intercultural segundo Candau (2008, p.23):

enfrenta os conflitos provocados pela assimetria de poder entre os diferentes grupos socioculturais nas nossas sociedades e é capaz de favorecer a construção de um projeto comum, pelo qual as diferenças sejam dialeticamente incluídas.

As questões que Candau (2009) nos deixa para reflexão são: como promover no cotidiano das escolas práticas que articulem igualdade e diferença? Práticas que não se esgotam no intraescolar e estejam relacionadas à movimentos de construção de sociedades diferentes, justas e democráticas?

c) Formação e prática com novos saberes e práticas.

Em termos de Formação de Professores para a educação inclusivaa demanda é pela superação da especializaçãocontida nos currículos dos cursos, ou seja, da centralização no que é específico de cada categoria da educação especial: deficiências, transtorno de desenvolvimento global ou altas habilidades, desconsiderando o comum entre elas, bem como ao que é comum à prática do magistério em geral.

Superar a fragmentação de conteúdos na área da Educação Especial (OMOTE, 1996) exige mudança de perspectiva teórica de uma visão metafísica, que dicotomiza os saberes, para uma compreensão dialética e histórica de mundo, articulando os saberes. Aponta, também, para uma formação mais abrangente, que possibilite ao educador atuar com diferentes tipos de categorias da educação especial e com processos pedagógicos diversificados.Formação e prática que conforme Oliveira (2002) considere:

- O processo formativo de construção do saber-fazer educativo dos professores no cotidiano escolar, que implica em processo de reflexão sobre a prática;

- A interação intersubjetiva com o outro (público alvo da educação especial ou não) no processo ensino-aprendizagem;

- As representações e imaginários envolvidos na prática docente, com a possibilidade de serem transformadas no processo pedagógico;

- A pessoa do professor e do aluno;

- O deslocamento das "dificuldades" dos discentes para as suas "potencialidades";

- As diversas diferenças: de capacidades, etnia, gênero e de classe;

- A complexidade das diversas categorias da Educação Especial;

- A realização de práticas investigativas.

- A proximidade com os sistemas educacionais e as práticas educativas das escolas.

- A relação entre a teoria e a prática no processo ensino- aprendizagem.

Formação e prática pedagógica que possibilitem ao educador transitar entre os saberes (sociais, éticos, políticos e culturais) do magistério e das diferentes áreas de conhecimento sobre a Educação Especial.

Oliveira (2014) destaca que os professores da educação especial de uma escola pública de Belém apontaram como demanda de formação continuada para a inclusão o estudo sobre teorias da aprendizagem e desenvolvimento, o conhecimento da área social, conhecimentos específicos sobre as deficiências e sobre a inclusão em geral, como a questão de gênero. Temas que visualizam os educandos em suas situações sociais, de classe, gênero e do magistério em geral, além de questões específicas da Educação Especial.

O trânsito entre os saberes, em diversos campos de conhecimento e envolvendo questões específicas da Educação Especial pressupõe em se repensar e reconstruir os currículos vigentes das escolas, superando a concepção de currículo reduzida ao conteúdo programático, para uma visão mais ampla, política e dinâmica de currículo. 
O currículo, na visão de Paulo Freire, envolve "a política, a teoria e a prática do que-fazer na educação, no espaço escolar, e nas ações que acontecem fora desse espaço, numa perspectiva crítico-transformadora" (SAUL, 2010, p.109). Isto significa que o currículo incorpora a vida cotidiana da escola e não apenas os conteúdos escolares.

Na verdade, a compreensão do currículo abarca a vida mesma da escola, o que nela se faz ou não se faz, as relações entre todos e todas as que fazem a escola. Abarca a força da ideologia e sua representação não só enquanto ideias, mas como prática concreta (FREIRE, 1995, p. 123).

Assim, a luta pela inclusão social pressupõe uma responsabilidade histórico-política e ética, em relação ao Outro, que implica em criticidade, opção e decisão, e que não pode deixar de estar presente tanto na formação quanto na prática pedagógica dos professores. Como nos diz Freire (2000, p. 67):

se estamos a favor da vida e não da morte, da equidade e não da injustiça, do direito e não do arbítrio, da convivência com o diferente e não de sua negação, não temos outro caminho senão vier plenamente a nossa opção. Encarná-la diminuindo assim a distância entre o que fizemos e o que fazemos.

Para Mantoan (2008, p. 62) o trabalho pedagógico na educação inclusiva deve estimular a capacidade de aprendizagem dos educandos, ajudando-os a vencer os obstáculos. "Parte-se da certeza de que as crianças sempre sabem alguma coisa, de que todo educando pode aprender, mas no tempo e do jeito que Ihes são próprios". Ações que desloca o olhar das limitações dos sujeitos para suas potencialidades e na possibilidade de aprendizagem dos educandos público-alvo da Educação Especial.

A educação inclusiva, então, tem de ser tema de estudos em todas as disciplinas dos Cursos de formação de professores, não ficando restrita às disciplinas específicas da área da educação especial, bem como precisa estar presente na formação continuada e na prática dos professores do ensino comum e da educação especial.

\subsection{O atendimento educacional na educação inclusiva}

O Decreto $N^{\circ} 7.611$, em seu Art. $2^{\circ}$, estabelece: "a educação especial deve garantir os serviços de apoio especializado voltado a eliminar as barreiras que possam obstruir o processo de escolarização de estudantes com deficiência, transtornos globais do desenvolvimento e altas habilidades ou superdotação" (BRASIL, 2011).

$\mathrm{O}$ atendimento educacional especializado é compreendido comoconjunto de atividades, recursos de acessibilidade e pedagógicos organizados institucional e continuamente, prestado das seguintes formas: I- complementar à formação dos estudantes com deficiência, transtornos globais do desenvolvimento como apoio permanente e limitado no tempo e na frequência dos estudantes às salas de recursos multifuncionais; II - suplementar à formação de estudantes com altas habilidades ou superdotação (ART. $1^{\circ} \S 1^{\circ}$ - BRASIL, 2011).

O atendimento educacional para a inclusão escolar perpassa pelos níveis e modalidades de ensino. Entretanto, no Brasil, a população que vem sendo atendida, mesmo com precariedades, em termos de atendimento educacional é a do ensino fundamental, há uma demanda em termos da educação infantil, ensino médio, ensino superior e educação de jovens e adultos. E essa demanda é crescente em regiões como a Amazônia. 
Em estudos realizados em dois municípios paraenses, em classes multisseriadas, Oliveira, França e Santos (2011) identificaram a ausência de políticas de atendimento educacional especializado em escolas multisseriadas do campo e, em especial, para a educação infantil e educação de jovens e adultos. Ausência de salas de recursos multifuncionais e de recursos didáticos básicos e de intérpretes, estando os alunos jovens e adultos público-alvo da Educação Especial, nas classes multisseriadas, como "encostados", isto é, presentes na escola, mas sem matrícula oficial.

Acrescenta-se o fato de que a política de atendimento educacional especializado em salas de recursos multifuncionais também vem sofrendo críticas pelos diferentes sujeitos das pesquisas, entre as quais:

a) não atende às demandas regionais, considerando que em regiões como a Amazônia, pelas grandes distâncias e precariedades de condições sociais, ambientais e estruturais, a política de salas de recursos multifuncionais não é vista como o caminho viável para a inclusão. Há demanda de novas estratégias políticas para a inclusão escolar em determinados locais da Amazônia, entre as quais as comunidades ribeirinhas, quilombolas, indígenas, entre outras;

b) os professores é que exercem funções múltiplas, não estando capacitados para essas funções, já que suas formações são especializadas e direcionadas para determinadas categorias da educação especial. Essa diversidade de funções é vista pelos docentes como não clareza do papel do professor na sala de recursos multifuncionais.

Mendes e Malheiro (2012, p. 363) consideram que:

\begin{abstract}
Os professores de educação especial assumem uma demanda excessiva nas salas de recursos multifuncionais, dado que o AEE recomendado abre um leque para o atendimento a alunos com diferentes tipos de deficiências, de diferentes níveis de escolaridade, não deixando tempo hábil para atuar com o professor da sala comum. Na sala de recursos o professor especializado terá a impossível tarefa de dar conta do AEE dos mais variados tipos de alunos, o que nos faz pensar se o termo "multifuncional" adotado pela política não seria um adjetivo atribuído mais ao professor do eu ao tipo de classe!
\end{abstract}

c) nem todas as escolas possuem salas equipadas e adequadas e quando possuem nem sempre os professores são formados para utilizar os recursos pedagógicos. As carências de recursos pedagógicos e de sua manutenção estão relacionadas à falta de política financeira para atender a demanda da Educação Especial;

d) o tempo de atendimento educacional especializado dos educandos é reduzido e não atende às necessidades dos educandos, constituindo-se algumas vezes como aulas de reforço;

e) a pouca interação entre os docentes das classes comuns e os das salas de recursos multifuncionais dificulta o processo de ensino-aprendizagem dos educandos, apesar de serem realizadas conversas entre os docentes sobre o acompanhamento do aluno, os seus avanços e dificuldades (OLIVEIRA, 2013). Os professores da sala comum reclamam que a Sala de Recursos Multifuncionais é utilizada apenas pelos docentes da educação especial, não tendo acesso a esse espaço educacional nem aos recursos pedagógicos existentes nela (OLIVEIRA, 2014). Batista (2008, p.128) destaca que o diálogo deve ser estabelecido entre os docentes das duas salas no atendimento educacional especializado para "descobrir saídas conjuntas de atuação em cada caso. A troca de experiências entre diversos profissionais é construtiva e necessária para o aprofundamento e melhor desempenho, seja do aluno, do professor ou do especialista".

Essas críticas apontam para a demanda de novas estratégias pedagógicas de atendimento educacional especializado na Educação Especial, que não fique restrita às salas de recursos multifuncionais. 
EDUCAÇÃO ESPECIAL/INCLUSIVA NO BRASIL | Ivanilde Apoluceno de Oliveira

\section{4 | CONSIDERAÇÕES FINAIS}

A educação inclusiva no Brasil é um anseio de educadores e movimentos sociais que lutam por uma escola pública, de qualidade, visando garantir o direito de todos à educação. Uma escola que respeite as diferenças individuais e culturais assumindo o processo de inclusão escolar e social de diversos segmentos populares entre os quais o público-alvo da Educação Especial.

A política de educação inclusiva implantada na Educação Especial aponta demandas significativas, em função do acesso à escola de novos sujeitos e das mudanças estruturais, de paradigmas e de práticas indicadas em documentos oficiais, bem como nas falas dos atores das escolas.

Demandas que perpassam por mudanças estruturais no sistema de ensino e nas escolas, que se dimensionam como complexas, e que se constituem em entraves para o processo de inclusão escolar. Há necessidade de mudanças de paradigma educacional, na formação de professores, nas práticas dos docentes em classe e no currículo, que os sistemas públicos de ensino e as universidades enquanto agências formadoras não estão dando conta de atender.

Pela complexidade e amplitude das ações para inclusão, que se estende para além da educação, nos defrontamos com muitas críticas, mas poucas propostas concretas de mudanças, tanto por parte dos sistemas municipais e estaduais, que reproduzem de forma universal e homogênea a política oficial do MEC, quanto pelas escolas, que reproduzem a lógica do sistema.

Precisamos avançar no debate, evidenciar as demandas, problematizar a política que não atende as especificidades regionais, mas sobretudo, apontar pistas, caminhos teóricos e metodológicos para a inclusão escola e social do aluno público-alvo da Educação Especial. 
EDUCAÇÃO ESPECIAL/INCLUSIVA NO BRASIL | Ivanilde Apoluceno de Oliveira

\section{Referências}

BRASIL. Decreto No 7.611. Brasília: Ministério da Educação, 17 de novembro de 2011.

BATISTA, Cristina Abranches Mota. Atendimento educacional especializado para pessoas com deficiência mental. MANTOAN, Maria Teresa Eglér (Org). O desafio das diferenças nas escolas. Rio de Janeiro: Petrópolis: Vozes, 2008.

CANDAU, Vera Maria (Org.) Didática: questões contemporâneas. Rio de Janeiro: Forma \& Ação, 2009.

Multiculturalismo e educação: desafios para a práticapedagógica. MOREIRA, Antonio Flávio; CANDAU, Vera Maria. Multiculturalismo: diferenças culturais e práticas pedagógicas. Petrópolis- RJ: Vozes, 2008.

CAVALCANTI, Ana Maria Leite. A inclusão do aluno com deficiência mental no ensino médio: desafios da prática pedagógica. In: MARTINS, Lúcia de Araújo Ramos (Org.) Escola inclusiva: pesquisa, reflexões e desafios. João Pessoa: Ideia, 2008.

FREIRE, Paulo. Pedagogia da indignação: cartas pedagógicas e outros escritos. 6e. São Paulo: UNESP, 2000. $19 \overline{9}$.

A educação na cidade. 2e. São Paulo: Cortez,

MACHADO, Rosângela. Educação inclusiva: revisar e refazer a cultura escolar. In: (Org.) O desafio das diferenças nas escolas. Petrópolis: Vozes, 2008.

MANTOAN, Maria Teresa Eglér. Ensinando a turma toda: as diferenças na escola. In: (Org.) O desafio das diferenças nas escolas. Petrópolis: Vozes, 2008.

MENDES, Enicéia Gonçalves; MALHEIRO, Cícera A. Lima. Salas de recursos multifuncionais: é possível um serviço "tamanho único" de atendimento educacional especializado? In: MIRANDA, Theresinha Guimarães; FILHO, Teófilo Alves Galvão (Orgs). O professor e a educação inclusiva: formação, práticas e lugares. Salvador: EDUFBA, 2012.
OLIVEIRA, Ivanilde Apoluceno de. Paulo Freire: gênese da educação intercultural no Brasil. Curitiba: CRV, 2015.

Relatório de pesquisa: atendimento educacional em salas de recursos multifuncionais da rede municipal de Belém e Marabá - Pará. Mimeo. Observatório Nacional de Educação Especial - ONEESP. Belém: UEPA, São Paulo: UFSCAR, 2014.

Relatório de pesquisa: a prática da escolarização inclusiva e o atendimento especializado na Amazônia Paraense. Mimeo. Belém: UEPA, 2013.

FRANÇA, Maria do Perpétuo Socorro Avelino; SANTOS, Tânia Regina Lobato dos Santos (Orgs). Edu-cação em classes multisseriadas na Amazônia: singularidade, diversidade e heterogeneidade. Vols I e II. Belém: Eduepa, 2011.

OLIVEIRA, Ivanilde Apoluceno de. Saberes, Imaginários e representações na educação especial: $A$ problemática ética da "diferença" e da exclusão social. Petrópolis, 2e. RJ: Vozes, 2005.

Saberes, Imaginários e Representações na construção do saber-fazer educativo de professores da educação especial. Tese de doutorado. 331f. Programa de Pós-Graduação em Educação - Currículo da Pontifícia Universidade Católica de São Paulo. São Paulo: PUC-SP, 2002.

OMOTE, Sadao. A importância da concepção de deficiência na formação do professor de educação especial. In: Formação do educador: dever do Estado, tarefa da Universidade. São Paulo: UNESP, 1996.

SAUL, Ana Maria. Currículo. 2e. STRECK, Danilo; REDIN, Euclides; ZITKOSKI, Jaime José (Orgs.). Dicionário Paulo Freire. Belo Horizonte: Autêntica, 2010. 